\title{
A STUDY OF ADAPTATION CAPACITY OF COASTAL DISASTERS DUE TO CLIMATE CHANGE IN ORDER TO STRENGTHEN SOUTHWEST AREA OF TAIWAN
}

\author{
Hsiang-Lan Juan ${ }^{1}$, Tai-Wen Hsu ${ }^{2}$, Yuan-Jyh Lan ${ }^{2}$, Yue-Chen Lin $^{3}$ and \\ Ching-Jer Huang ${ }^{2}$
}

\begin{abstract}
The adaptive capacity of coastal disasters caused by climate change in order to strengthen southwestern Taiwan against natural calamities in the future is investigated in this paper. In Taiwan, the coastal zone suffers from approximately four typhoons each year, and the exceptionally high sea levels caused by storm surges frequently results in coastal disasters and hinders the development of the coastal area. The problems of rising sea levels and frequent typhoons induced by climate change have threatened the Taiwanese coastal environments. These influences as well as serious land subsidence upon a scenario year were carried out in the coastal areas near the cities of Chiayi and Tainan in Taiwan. The present study focuses on the construction of the disaster characteristics on Chiayi and Tainan Coasts, model establishment for situation analysis of water environmental factors, impact estimation and indefinite analysis on disasters, and vulnerability and risk estimation of coastal disasters. An understanding of the marine and meteorological characteristics in coastal zones is conducive to raising the efficiency of the defense against coastal disasters. These results could provide useful information to establish strategies to implement as well as how to analyze the benefits of such a program.
\end{abstract}

Keywords: climate change, coastal disaster, adaptation capacity, vulnerability, risk

\section{INTRODUCTION}

Taiwan is adjoined on the west by the Taiwan Strait, on the east by the Pacific Ocean and on the south by the Bashi Channel. Taiwan is located at the hub of the Western Pacific typhoon track. An annual average of 3.75 typhoons hits the island, according to records collected over the past century. Global warming impacts marine life and is causing the sea level to rise. It also affects typhoon frequency, an issue that will have an influence on the environment we live in. Governments and scientists have given wide attention to the impacts of waves and storm surges on human activities. The statistical data of typhoons hitting Taiwan over the past 40 years (Figure 1) shows that the frequency of Western Pacific typhoons has been gradually increasing. Strong winds, heavy rain and huge waves induced by typhoon are the main causes of the rise of local sea levels in coastal areas. According to the typhoon statistics published by the Central Weather Bureau of Taiwan, shown in Figure 2, the annual minimum typhoon pressure has decreased and the maximum wind speed near the typhoon center increased gradually over the past decade. In addition, research of long-term sea level rising caused by climate change indicates that the rate of the rise of the global sea level is $+3.32 \mathrm{~mm} /$ year. Climate change in coastal areas may have several impacts (Figure 3), including increases in the pressure gradient, wind speed, path and frequency of typhoons, precipitation changes, increases in tidal levels and a generally rising sea level. These impacts can induce larger typhoon waves and surge levels, the wave-breaking line will tend to migrate shoreward, increasing the probability of wave overtopping and coastal floods, which together will lead to coastal erosion. Sea level rises can induce results that are even more serious.

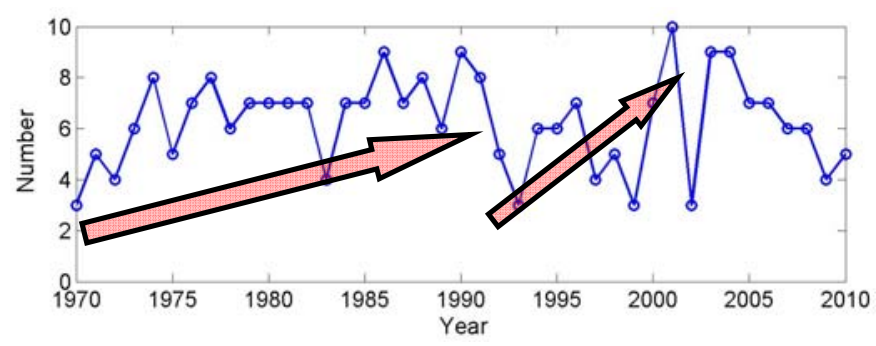

Figure 1. The frequency of typhoons hitting Taiwan over the past $\mathbf{4 0}$ years.

\footnotetext{
${ }^{1}$ Water Resources Agency, Ministry of Economic Affairs, 9-12F 41-3 Sec.3 Hsin-yi Rd., Taipei 106, TAIWAN (ROC)

2 Dept. of Hydraulic and Ocean Engineering, National Cheng Kung University, 1 University Rd., Tainan 701, TAIWAN (ROC)

${ }^{3}$ Dept. of Leisure Resources and Green Industries, University of Kang Ning, No.188, Sec. 5, Anzhong Rd., Annan Dist., Tainan 709, TAIWAN (ROC)
} 
Therefore, this study aims to investigate the adaptive capacity of coastal areas following disasters caused by climate change so as to find ways to proactively strengthen Taiwan's coasts against natural calamities in the future. The investigative area of focus is the southwestern area of Taiwan (the Chiayi and Tainan coastal region) as shown in Figure 4. The purpose of this paper is to develop a model for scenario analysis of environmental factors, estimating the coastal vulnerability and disaster risk to Taiwan, and establish disaster vulnerability and risk maps which take into account the increased vulnerability of the area due to climate change.

(a) Annual Minimum Typhoon Pressure

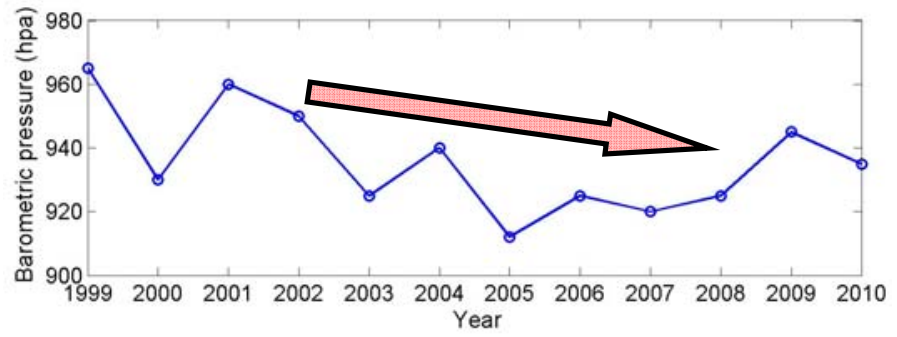

(b) Annual Maximum Wind Speed near Typhoon Center

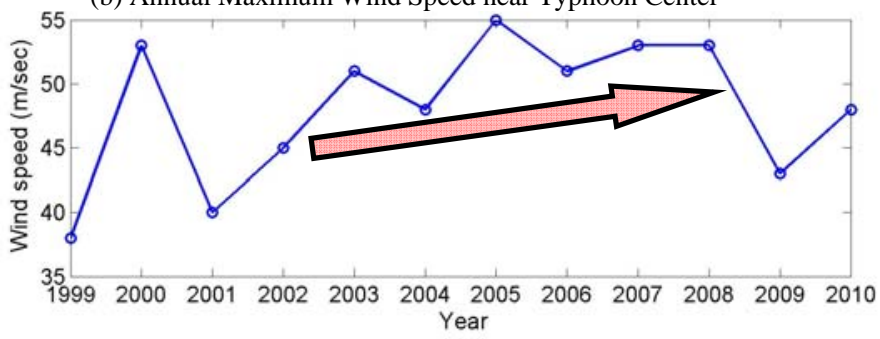

Figure 2. Typhoons hitting Taiwan in the past 10 years.

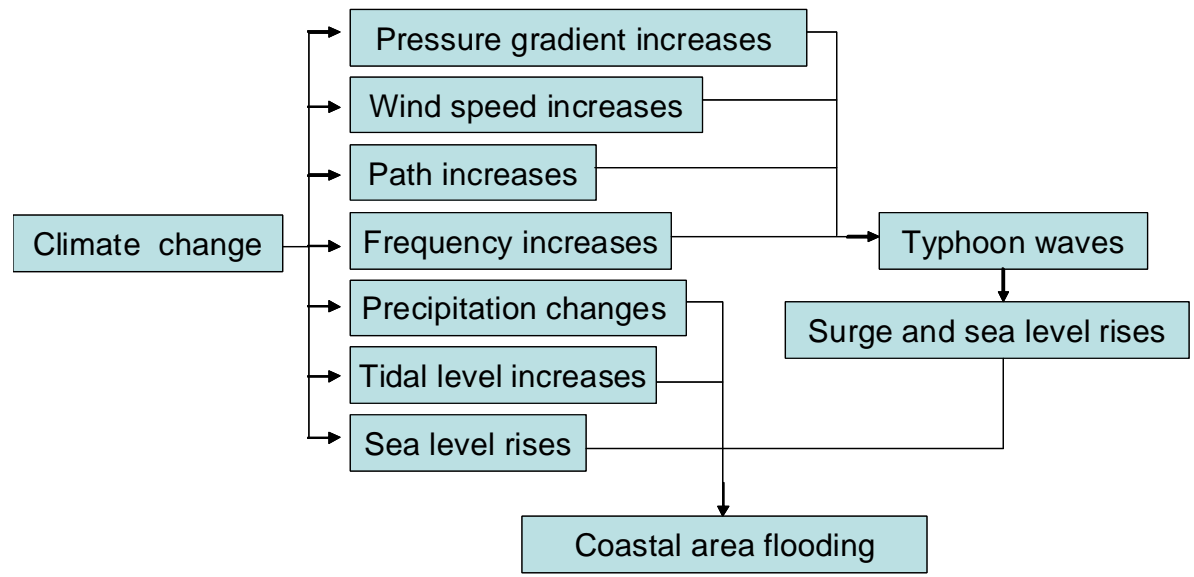

Figure 3. The Impacts of climate change on coastal areas.
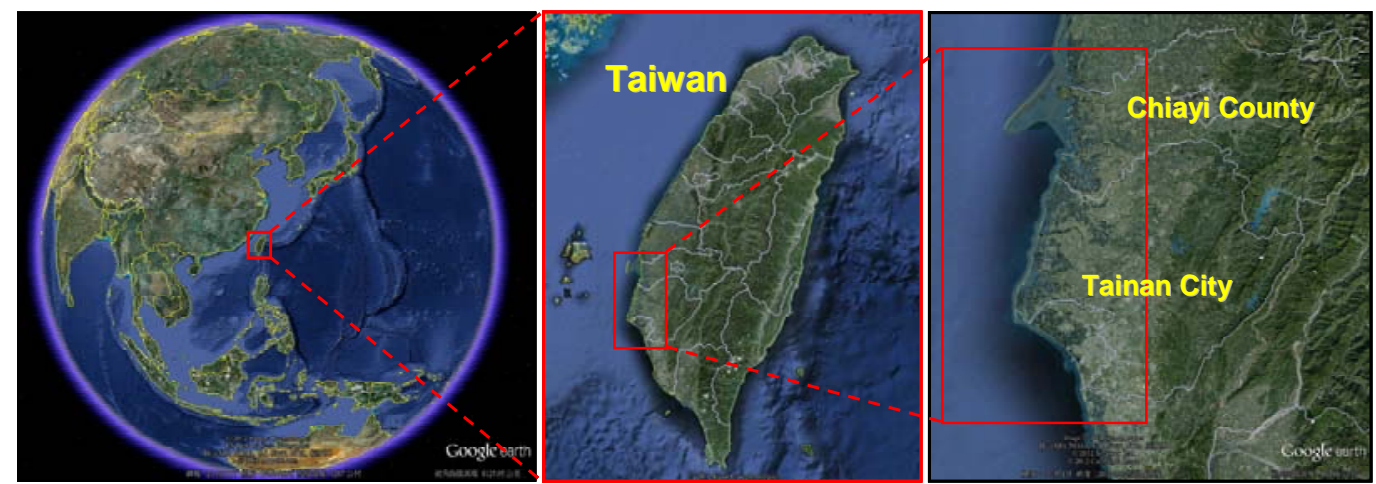

Figure 4. The southwest coast (Chiayi and Tainan) of Taiwan. 


\section{COASTAL RISK ASSESSMENT}

Human beings living in coastal areas are relatively more vulnerable to the impact of storms, waves, tides and rises in sea level. Due to global warming and climate change, the likelihood and danger of rising of sea levels and other related issues are obvious. Disaster risk assessment requires holistic consideration, including overall vulnerability and hazard analysis. In addition to the physical factors, economic, social and environmental factors should be incorporated into the investigation. The United Nations Disaster Relief Organization (UNDRO) proposes an operational definition for disaster risk in the Natural Disasters and Vulnerability Analysis Report in 1979 (UNDRO, 1980):

$$
R=H \text { (hazard) } \times V \text { (vulnerability) }
$$

Equation (1) represents the relationship between disaster risk factor (R), hazard potential $(H)$ and vulnerability (V). The hazard potential factor refers to the variability of disasters. In general, an increase in disaster intensity and frequency causes more serious damage and loss. The exposure of the affected objects refers to all people and property possibly threatened by the hazard factors, such as local citizens, livestock, houses, crops, and so on. An area with greater property density exposed to the risk factors will be subjected to greater loss potential. Vulnerability refers to the possibility of property injury or loss induced by potential disaster factors in a given hazardous area. The greater the vulnerability the greater the possible losses and higher disaster risk (Cutter, 1996). Adaption capacity signifies the ability to adapt to a series of measures taken by governments and individuals in order to prevent and reduce the risk of disasters. Stronger adaption capacity leads to lower disaster risk. According to the basic concept of disaster risk assessment proposed by the National Science and Technology Center for Disaster Reduction in Taiwan (NCDR), vulnerability has social, environmental, physical and economic characteristics; the hazard potential has geophysical, meteorological, biological, environmental and technological characteristics.

The first idea of coastal vulnerability assessment, proposed in 1991 by the IPCC Coastal Zone Management (CZM), is defined as a country has the ability enough to cope with a rise in sea level. UNEP (2005) proposes that the vulnerability assessment can be divided into two phases. The first phase is one in which the DPSIR (Driving Force-Pressure-State-Impact-Response) model is applied to assess the coastal vulnerability related to socio-economic indicators, pressure, and the status of critical environmental factors. These factors include the population distribution and density in the coastal area, the land distribution and land use, and the probability of natural disasters (e.g. typhoons, waves and tides). The second phase is to estimate the vulnerability of the affected population in the coastal area, land distribution, susceptibility to disasters, landscape and the topographical terrain and how it may be affected by climate change.

Figure 5 shows the coastal disaster and vulnerability indicators utilized in present study. Coastal hazard potential includes the four Coastal Hazard Indexes (CHI) concerned in storm surges and floods in coastal areas caused by typhoons. The coastal vulnerability is classified into 13 Coastal Vulnerability Indexes (CVI) in the three domains of artificial facilities, environmental geography and socio-economic factors. Each indicator is surveyed by experts and scholars in Taiwan. It is noted that the typhoon surges, wave set-up and overtopping as well as land subsidence are the special vulnerable problems in southwestern coasts of Taiwan.

A five-class system is employed to divide the assessment results of hazard potential and vulnerability into five grades (1: very low, 2: low, 3: medium, 4: high, 5: very high) for making the hazard and vulnerability maps. The five-class risk map can be created by using equation (1). 


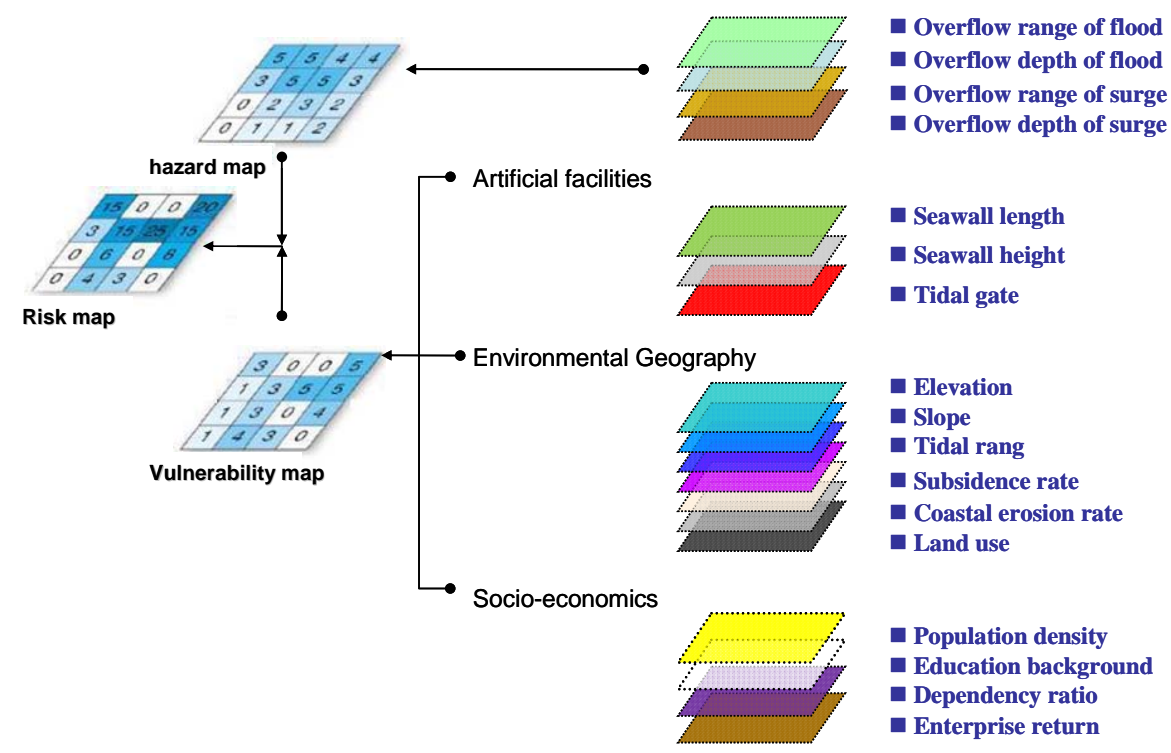

Figure 5. Level diagram of coastal disaster and vulnerability indicators.

As to hazard potential and vulnerability assessment, we define $I_{(i, j)}$ the $j^{\text {th }}$ CVI or CHI index of the $i^{\text {th }}$ domain, $R_{(i, j)}$ the index value of $I_{(i, j)}$ and $R_{(i, j)}^{*}$ the normalized index value may be formulated as:

$$
R_{(i, j)}^{*}=\frac{R_{(i, j)}-\min \left\{R_{(i, j)}\right\}}{\max \left\{R_{(i, j)}\right\}-\min \left\{R_{(i, j)}\right\}}
$$

in which $\max \left\{R_{(i, j)}\right\}$ and $\min \left\{R_{(i, j)}\right\}$ are the maximum and the minimum $R_{(i, j)}$, respectively. The impact factor of the $i^{\text {th }}$ domain $F_{i}$ is estimated through a weighting-summation treatment, as the following:

$$
F_{i}=\sum_{j=1}^{J_{i}} w_{(i, j)} \times R_{(i, j)}^{*}
$$

where $J_{i}$ is the total index number of the $i^{\text {th }}$ domain, and $w_{(i, j)}$ is the weighting of the $j^{\text {th }}$ index of the $i^{\text {th }}$ domain estimated by the AHP (Analytic Hierarchy Process) evaluation in this study.

The impact factor of coastal hazard potential $(H)$ can be assessed from equations (2) and (3). The coastal vulnerability includes artificial facilities, environmental geography and socio-economics. We also utilize the weighting-summation formula to evaluate the entire impact factor of coastal vulnerability $(V)$ :

$$
V=\sum_{i=1}^{3} p_{(i)} \times F_{(i)}
$$

where $p_{i}$ is the weighting on the $i^{\text {th }}$ domain of coastal vulnerability.

The AHP is a structured technique for organizing and analyzing complex problems. The processing steps are outlined as follows: (1) statements about the assessment problems; (2) confirmation of all impact factors; (3) establishing a hierarchical relationship; (4) constructing the paired comparison matrix; (5) calculation of the eigenvectors, the maximum eigenvalue and the priority vector; (6) consistency test verification; (7) the hierarchy weighting calculation; (8) providing the decision-making information. For detailed description of AHP theory, please refer to Lin and Tang (2003).

The flowchart of an actual calculation is shown in Figure 6. The Geographic Information System (GIS) is used for the calculation, analysis and display tools in the present investigation. The input information, stored by the vector- or grid-type data structures, has been converted to a grid format for the hazard potential and vulnerability assessment. Through regression, combination, and vector-type transformation, the final estimated results can be given. 


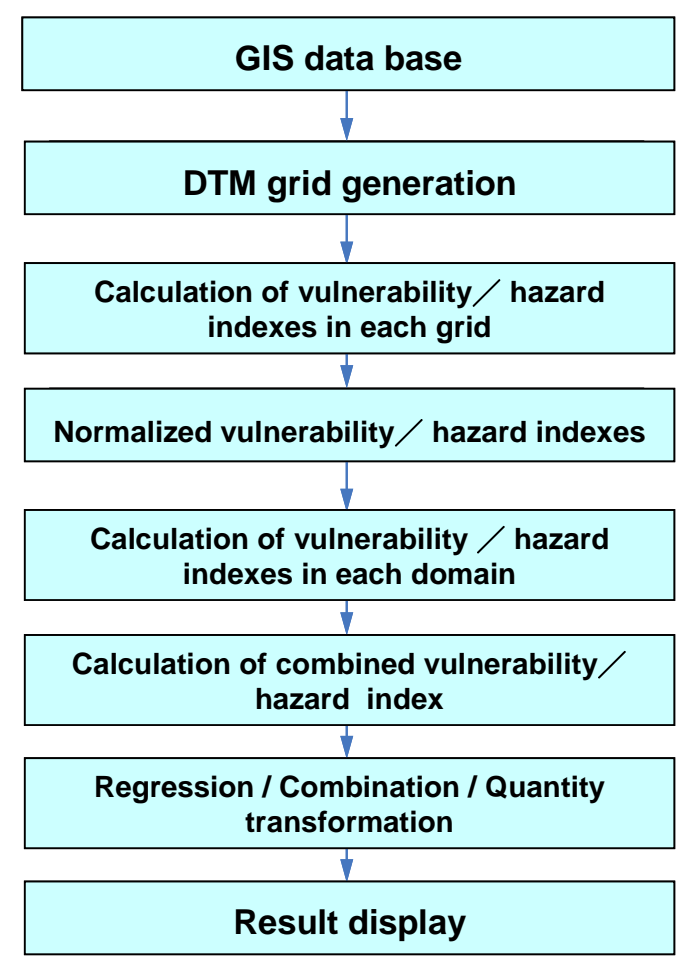

Figure 6. Flowchart of assessment of coastal vulnerability and hazard potential.

\section{COASTAL HAZARD INDEX (CHI)}

The hazard potential is divided into two parts, deluge and typhoon surge flood. In order to allow the hazards to more closely fit the specific situation of the threats of typhoons in Taiwan, the coastal overflow should be considered as precipitation, sea level rise, storm surge as well as the wave run-up and overtopping. In this study, the coastal overflow model, including the above influence factors, is employed to estimate the results of the Coastal Hazard Indexes (CHI). Figure 5 shows the $\mathrm{CHI}$ items, including the overflow range of flood, the depth of flood, the overflow range and depth of surge, and their weightings according to the survey of experts and scholars are listed in Table 1.

\begin{tabular}{|c|c|c|}
\hline \multicolumn{2}{|c|}{ Table 1. AHP evaluation on the index weighting of hazard analysis in southwest coastal area of Taiwan. } \\
\hline Level & Index & Weighting \\
\hline \multirow{3}{*}{ Hazard Potential } & The overflow range of flood & 0.384 \\
\cline { 2 - 3 } & The depth of flood & 0.271 \\
\cline { 2 - 3 } & The overflow range of surge & 0.159 \\
\cline { 2 - 3 } & The depth of surge & 0.186 \\
\hline
\end{tabular}

P.S.: Consistency ratio C.R. $=0.02<0.1$

\section{COASTAL VULNERABILITY INDEX (CVI)}

The Coastal Vulnerability Index (CVI) refers to a country or regions specific relative weakness of exposure to natural disasters and their ability in handling them when they do occur. The formation of coastal areas is a dynamic and complex physical process. CVI can provide the understanding of relative changes in future sea levels. It also can be regarded as the theoretical basis for estimating the coastal hazards and sea-level rise caused by climate change. UNEP (2005) proposes that CVI indicators, directed against the impact of the rising sea-level, should include the population density in coastal areas, the probability of natural disaster incidents, the percentage of vegetation cover, the geographic exposure, and the human development index. Özyurt (2007) points out that the CVI development must be accomplished from the standpoint of different goals, processes, spatial and temporal scales and the present information in that locality. 
In this study, the determination of appropriate CVI indicators for Taiwan's coasts is based upon work done by Doukakis (2005), Hong et al. (2006), Kavi Kumar and Tholkappian (2006) and UNEP (2005), and considered from the current state of Taiwan's environment. Based on the results of an AHP evaluation according to surveys of experts and scholars in civil engineering, hydraulic engineering and marine environmental science, we constructed, classified and quantified a total of thirteen CVI indicators into three domains of artificial facility, environmental geography and socioeconomics, as shown in Table 2. The artificial facility domain refers to the protection facilities of the hydraulic engineering structures, including the relative ratios of seawall length, seawall height, and tidal gates. The environmental geography domain includes the elevation of the coastal area, the slope, tidal range, land subsidence rate, coastal erosion rate and land use (for ports, industrial zones, agricultural areas, national parks, etc.). In the socio-economic domain, the population density, education background, dependency ratio, and enterprise return are taken into consideration. Table 2 shows the environmental geography domain is weighted at 0.548 . The artificial facility is the next significant vulnerability domain, weighted at 0.327 , and the socio-economic domain has the lowest weighting of 0.125 .

Table 2. AHP evaluation on the index weighting of vulnerability analysis in southwest coastal area of Taiwan.

\begin{tabular}{|c|c|c|c|c|}
\hline Level & Domain & Weighting & Index & Weighting \\
\hline \multirow{13}{*}{ Vulnerability } & \multirow{3}{*}{ Artificial Facility } & \multirow{3}{*}{0.327} & Relative ratio of seawall length & 0.257 \\
\hline & & & Relative ratio of seawall height & 0.499 \\
\hline & & & Relative ratio of tidal gate & 0.244 \\
\hline & \multirow{6}{*}{$\begin{array}{l}\text { Environmental } \\
\text { Geography }\end{array}$} & \multirow{6}{*}{0.548} & Elevation & 0.138 \\
\hline & & & Slope & 0.098 \\
\hline & & & Tidal range & 0.086 \\
\hline & & & Rate of land subsidence & 0.226 \\
\hline & & & Rate of coastal erosion & 0.359 \\
\hline & & & Land use & 0.093 \\
\hline & \multirow{4}{*}{ Socio-economics } & \multirow{4}{*}{0.125} & Population density & 0.415 \\
\hline & & & The relative value of education & 0.223 \\
\hline & & & The rate for giving support to the elder & 0.166 \\
\hline & & & Enterprise return & 0.196 \\
\hline
\end{tabular}

P.S.: Consistency ratio C.R. $=0.02<0.1$

\section{RESULTS AND DISCUSSION}

\section{(a) Basic data investigation and scenario analysis period}

For studying and assessing the coastal vulnerability and disaster danger in the southwest coast of Taiwan caused by climate change, the basic data regarding the coastal regions have been collected and analyzed, such as the investigation and collection of data on the current situation of coastal disaster prevention facilities, the economic losses caused by coastal disasters, land use and socio-economics, the scenario simulation on run-up and overtopping of typhoon wave by climate change, and the climate change impact evaluation on coastal hazard, etc.. The analysis periods, in accordance with the suggestion of NCDR, are 1980-1999 for base years and 2020-2039 for scenario years.

The rising of sea levels due to climate change has been analyzed using three methods: Fourier transformation, linear regression extrapolation, and Ensemble Empirical Mode Decomposition (EEMD). Figure 7 shows that the sea level of the southwest coast of Taiwan is rising. The estimation of sea level trend in southwest coast (Chiayi and Tainan) of Taiwan is summarized in Table 3. The average sea level rise will increase somewhere in the range of 10.19 to $14.57 \mathrm{~cm}$ in the period between 2020-2039. 
(a1) Comparison of measured data by FFT and regression analysis (Wungang station)

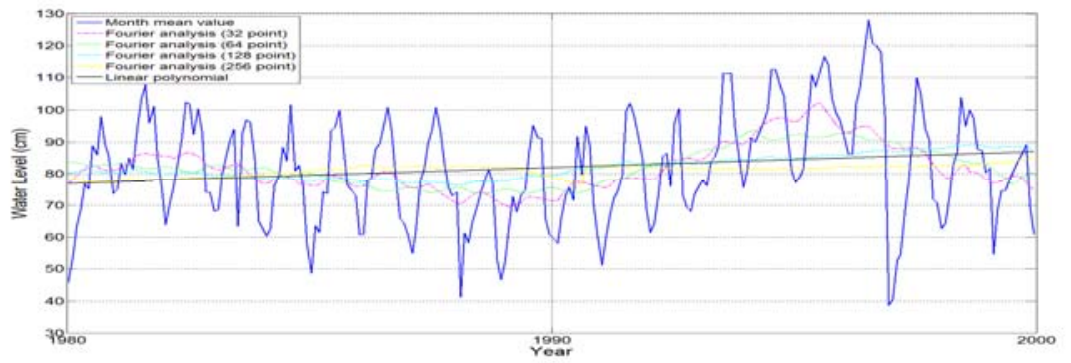

(a2) Trend prediction of the regression analysis and EEMD method (Wungang station)

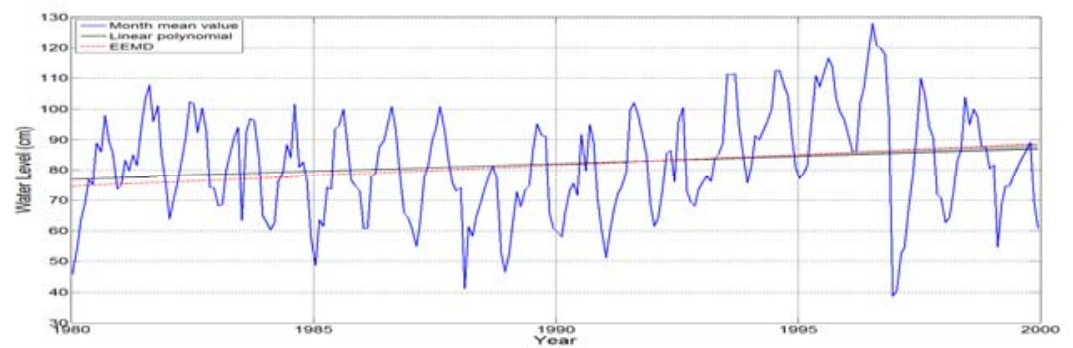

(b1) Comparison of measured data by FFT and regression analysis (Jiangjyun station)

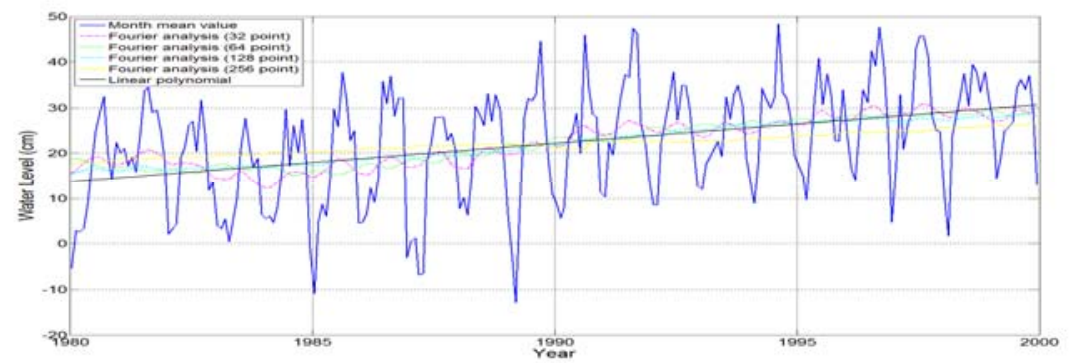

(b2) Trend prediction of the regression analysis and EEMD method (Jiangjyun station)

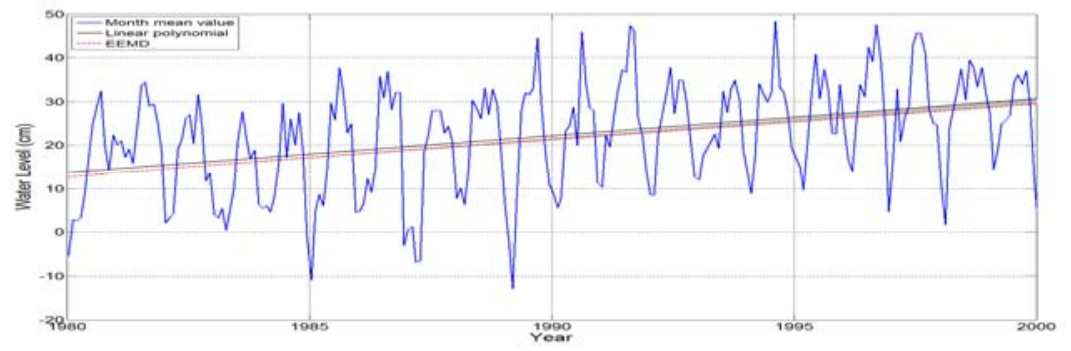

Figure 7. Prediction of mean sea rise in southwest coast (Chiayi and Tainan) of Taiwan.

\begin{tabular}{|c|c|c|c|c|c|}
\hline \multicolumn{6}{|c|}{ Table 3. The estimation of sea level trends in southwest coast (Chiayi and Tainan) of Taiwan. } \\
\hline Tidal Station & $\begin{array}{c}\text { Analysis of the } \\
\text { base period (yr) }\end{array}$ & $\begin{array}{c}\text { Regression } \\
\text { analysis }\end{array}$ & FFT & EEMD & Average \\
\hline Wungang & $1980-1999$ & $9.92 \mathrm{~cm}$ & $6.74 \mathrm{~cm}$ & $13.90 \mathrm{~cm}$ & $10.19 \mathrm{~cm}$ \\
\hline Jiangiyun & $1980-1999$ & $16.96 \mathrm{~cm}$ & $9.10 \mathrm{~cm}$ & $17.66 \mathrm{~cm}$ & $14.57 \mathrm{~cm}$ \\
\hline
\end{tabular}

In the simulation of run-up and overtopping by typhoon waves due to climate change, the different return periods of wave height and tide level during a recent time frame (1980-1999) as well as scenario stage (2020-2039) are estimated for the input data of model computing. Figure 8 shows a case of the run-up and overtopping simulations for considering sea level rise from 2020 to 2039 and the typhoon wave with a 250-year return period. 
The problem of land subsidence is serious on the southwestern coast of Taiwan. According to the analyzed data from 1991 to 2009, the cumulative subsidence depths in Chiayi Coast and north coastal area of Tainan are significant (Figure 9).
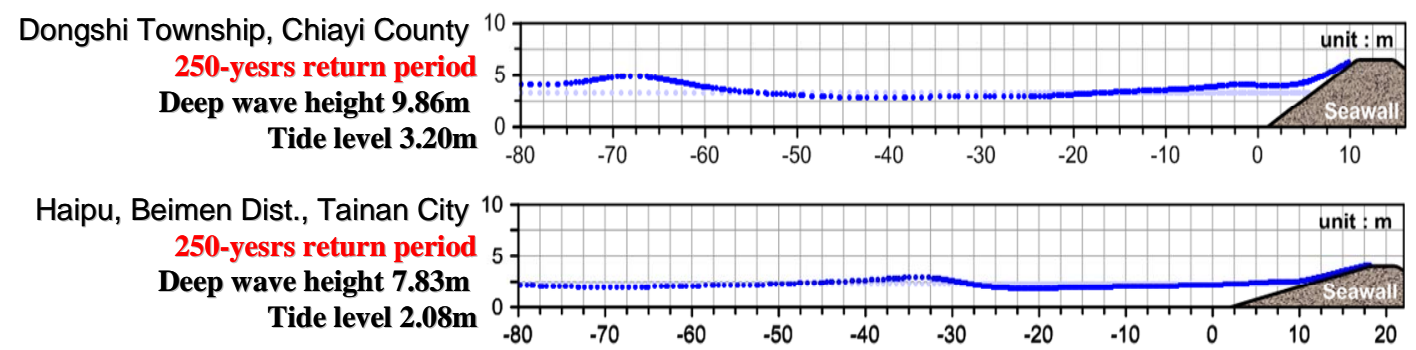

Cing cao lun, Annan Dist., Tainan City ${ }^{10}$
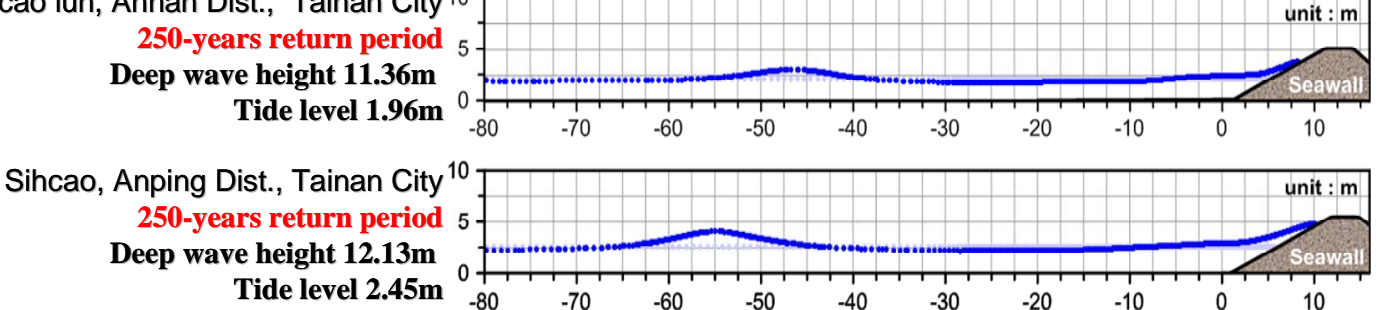

PS : Sea level rise $14.57 \mathrm{~cm}$ from 2020 to 2039 (the most serious scenario)

Figure 8. The wave run-up of the southwest coast in Taiwan considering sea level rise from 2020 to 2039 and the typhoon wave with 250 -years return period.

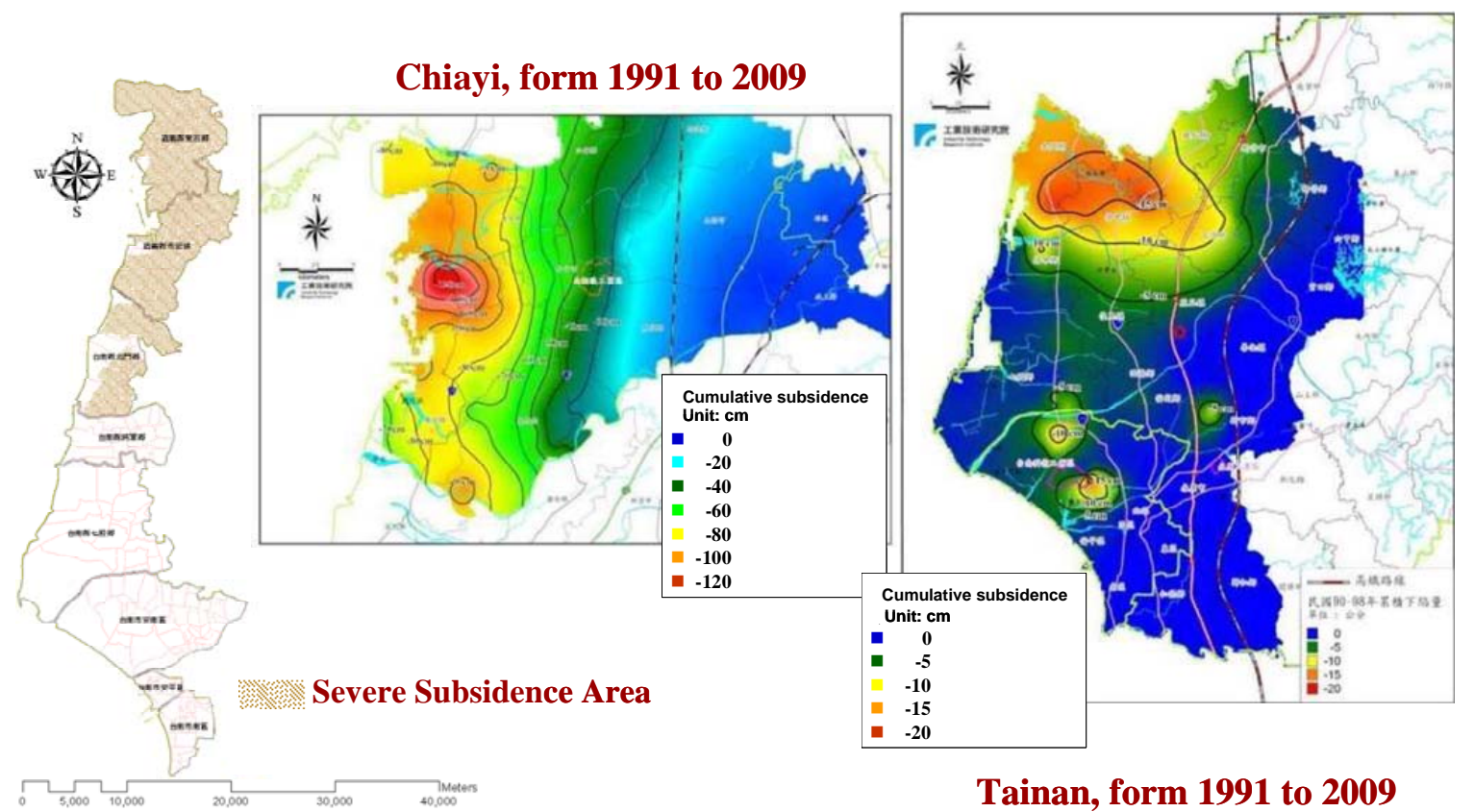

Figure 9. The subsidence area and cumulative depth in Chiayi and Tainan from 1991 to 2009.

(b) The coastal vulnerability assessment due to climate change

The coastal vulnerability assessment in Chiayi and Tainan coastal areas by equal and AHP weightings are analyzed and compared in Figures 10-14. Figures 10 and 11 show the three vulnerability domains for present conditions using equal and AHP weightings, respectively. Figure 12 and 13 illustrate the three vulnerability domains for this scenario's conditions using equal and AHP 
weightings. Figure 14 exhibits the final results of the vulnerability analysis for the Chiayi and Tainan coastal areas. It is notable that the vulnerability assessments by equal weighting analysis and AHP analysis have significant differences. AHP weighting, which is obtained from the survey conducted by experts and scholars, reflects the unique features of the environment and culture in Taiwan.

Table 4 lists the coastal vulnerability of Chiayi and Tainan's coasts. Looked at together, they have a vulnerability level of 4-5 based on AHP weighting. The vulnerability domains of artificial facilities and environmental geography are significantly affected by climate change in the Chiayi Coast, while the artificial facilities and socio economic domains are mainly affected in the southern region of Tainan's Coast. The northern region of Tainan's Coast is comparatively less vulnerable.

\section{(c) Coastal hazard assessment due to climate change}

The CHI assessments done through an AHP analysis of the southwestern coast of Taiwan (Chiayi and Tainan) are illustrated in Figure 15. Figure 15(A) reveals that the main flooded areas in their present condition are located along the coast and include lagoons and lowlands of river banks. In scenario condition (2020-2039), as shown in Figure 15(B), the flood area and general water depth will be significantly increased. Figure 16 presents the current and scenario hazard potential of Chiayi and Tainan coasts, superimposed from Figure 15 by equal and AHP weightings, respectively. The results of the current hazard potential achieved using equal and AHP weightings are similar (see Figure 16(A)). Both equal and AHP weightings of hazard potentials increase during the time frame of the scenario situation (see Figure 16(B)); however, the more raised degree by equal-weighting analysis than AHP-weighting analysis indicates that the equal-weighting analysis may overestimate the coastal disaster in southwestern Taiwan.

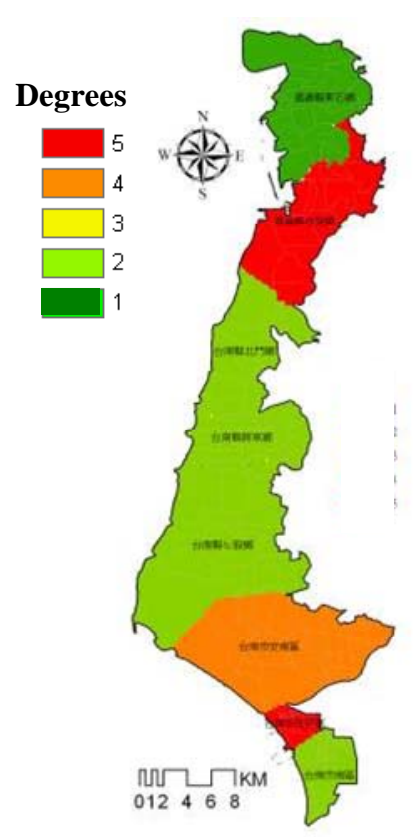

(a) Artificial facilities

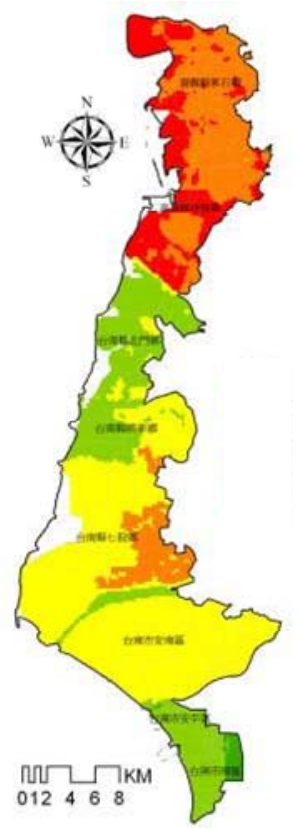

(b) Environmental Geography

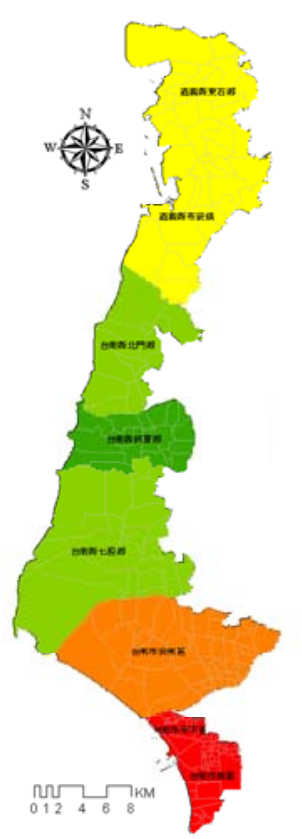

(c) Socio-economics

Figure 10. The vulnerability of three domains in Chiayi and Tainan coastal areas - (present and equal weighting). 


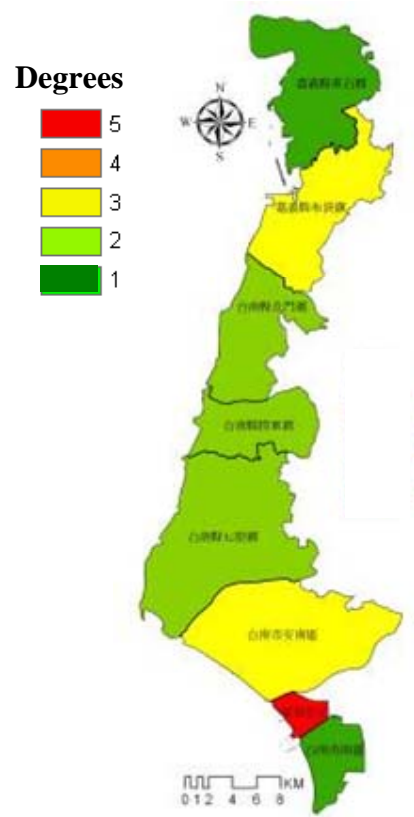

(a) Artificial facilities

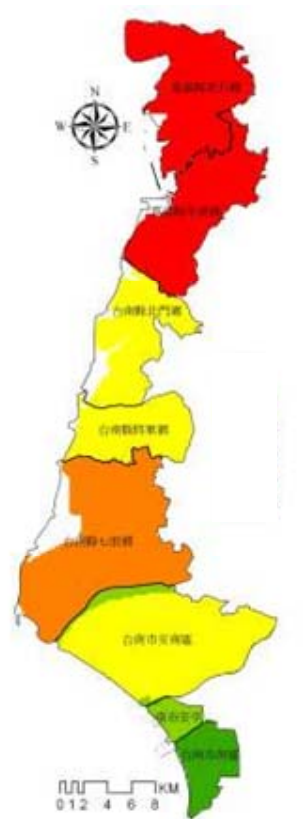

(b) Environmental Geography

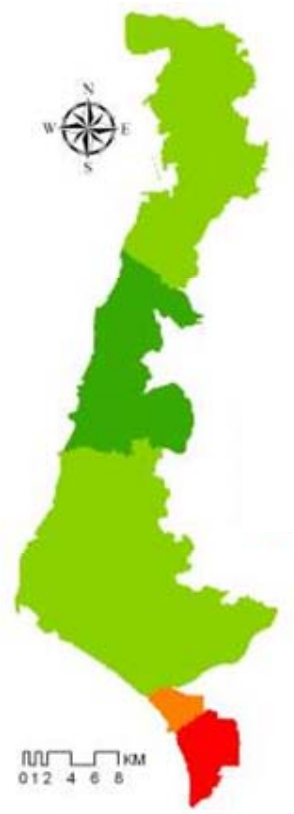

(c) Socio-economics

Figure 11. The vulnerability of three domains in Chiayi and Tainan coastal areas - (present and AHP weighting).

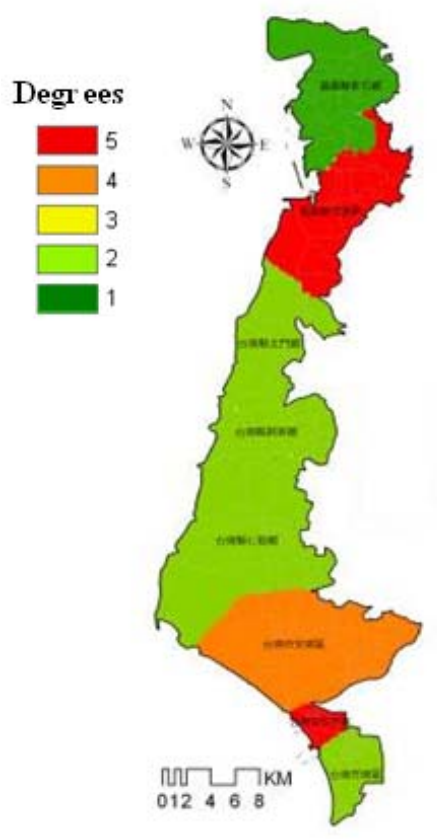

(a) Artificial facilities

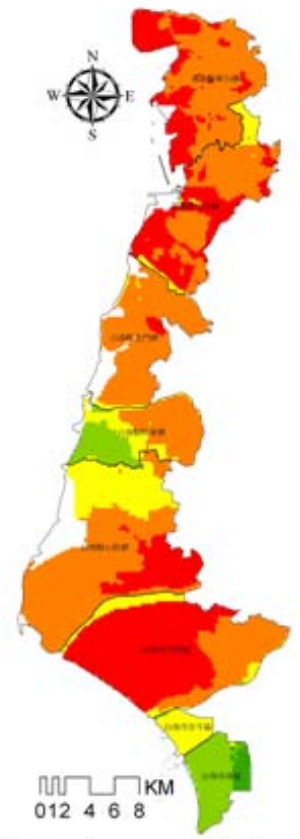

(b) Environmental Geography

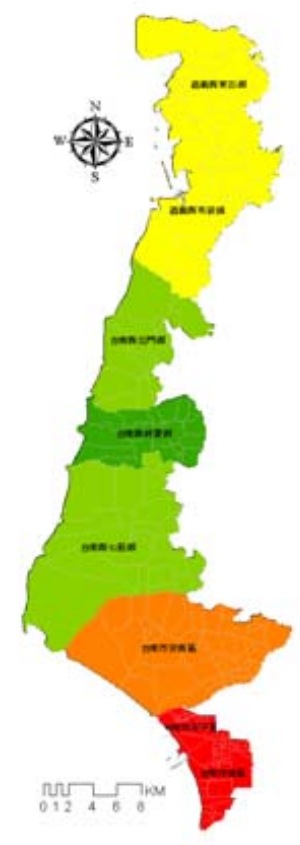

(c) Socio-economics

Figure 12. The vulnerability of three domains in Chiayi and Tainan coastal areas - (scenario and equal weighting). 


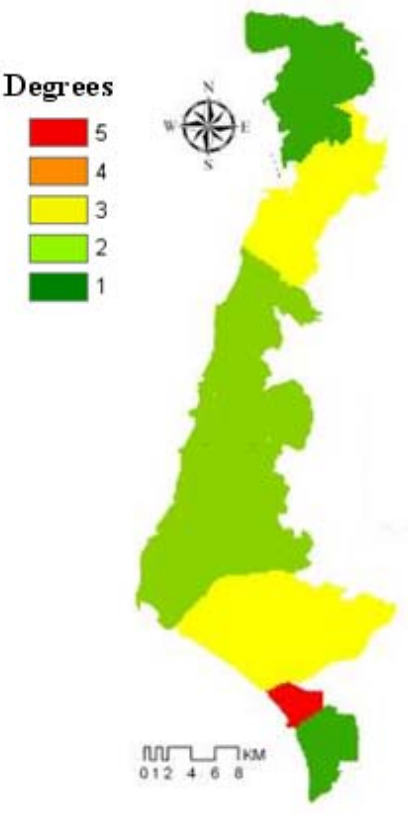

(a) Artificial facilities

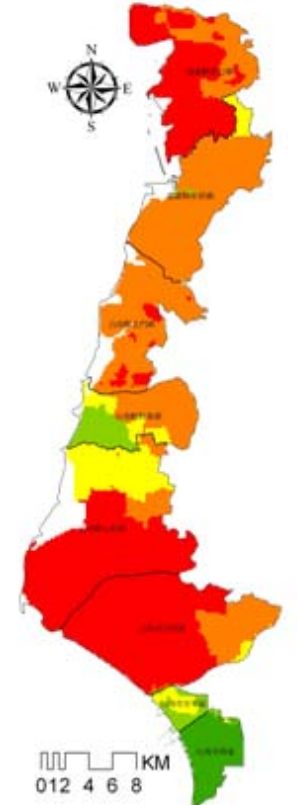

(b) Environmental Geography

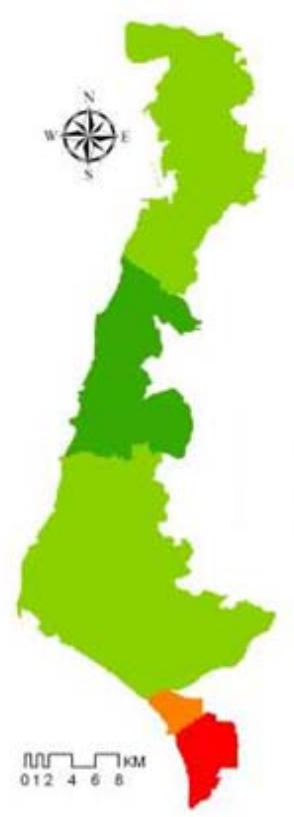

(c) Socio-economics

Figure 13. The vulnerability of three domains in Chiayi and Tainan coastal areas - (scenario and AHP weighting).

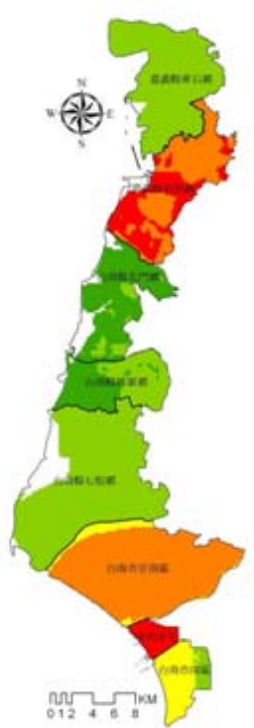

$\begin{array}{ll}\text { (a) Equal weighting } & \text { (b) AHP weighting }\end{array}$

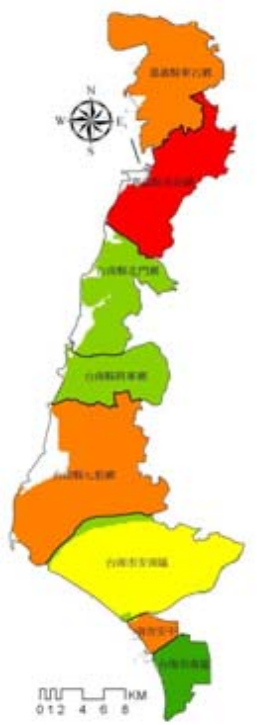

(b) AHP weighting

(present)

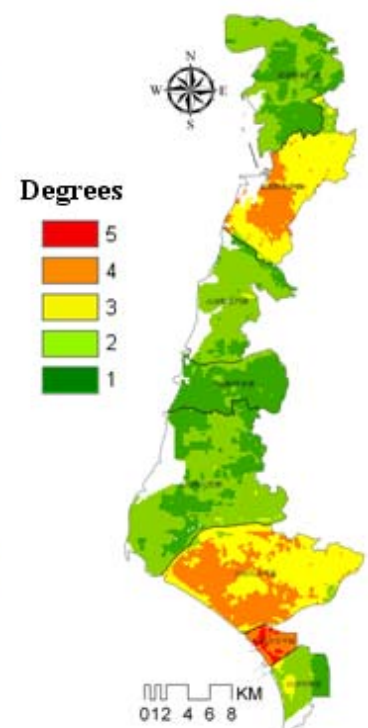

(a) Equal weighting

(B) Coastal vulnerability analysis (scenario)

Figure 14. The results of vulnerability analysis in Chiayi and Tainan coastal areas. 


\begin{tabular}{|c|c|c|c|c|c|c|c|c|}
\hline \multirow[b]{2}{*}{ Items } & \multicolumn{2}{|c|}{ Chiayi County } & \multicolumn{3}{|c|}{ Tainan City (North region) } & \multicolumn{3}{|c|}{ Tainan City (South region) } \\
\hline & $\begin{array}{l}\text { Dongshi } \\
\text { Township }\end{array}$ & $\begin{array}{c}\text { Budai } \\
\text { Township }\end{array}$ & $\begin{array}{c}\text { Beimen } \\
\text { Dist. }\end{array}$ & $\begin{array}{l}\text { Jiangjun } \\
\text { Dist. } \\
\end{array}$ & $\begin{array}{l}\text { Qigu } \\
\text { Dist. }\end{array}$ & $\begin{array}{l}\text { Annan } \\
\text { Dist. }\end{array}$ & $\begin{array}{l}\text { Anping } \\
\text { Dist. }\end{array}$ & $\begin{array}{l}\text { South } \\
\text { Dist. }\end{array}$ \\
\hline $\begin{array}{c}\text { Relative ratio of } \\
\text { seawall length }\end{array}$ & & $\mathrm{X}$ & & & & & $X$ & \\
\hline $\begin{array}{l}\text { Relative ratio of } \\
\text { seawall height }\end{array}$ & & & & & & & $X$ & \\
\hline $\begin{array}{l}\text { Relative ratio of } \\
\text { tidal gate }\end{array}$ & & $\mathrm{X}$ & & & & & & \\
\hline Elevation & $\mathrm{x}$ & $\mathrm{x}$ & $\mathrm{x}$ & $\mathrm{X}$ & $\mathrm{x}$ & $\mathrm{X}$ & $\mathrm{X}$ & $\mathrm{X}$ \\
\hline Slope & $\mathrm{X}$ & $\mathrm{X}$ & $\mathrm{X}$ & $\mathrm{X}$ & $\mathrm{X}$ & $\mathrm{X}$ & $\mathrm{X}$ & $\mathrm{X}$ \\
\hline Tidal range & $\mathrm{X}$ & $\mathrm{X}$ & & & & & & \\
\hline $\begin{array}{l}\text { Rate of land } \\
\text { subsidence }\end{array}$ & $X$ & $X$ & & & & & & \\
\hline Rate of coastal erosion & $\mathrm{X}$ & $\mathrm{X}$ & $\mathrm{X}$ & $\mathrm{X}$ & $\mathrm{X}$ & $\mathrm{X}$ & $\mathrm{X}$ & $\mathrm{X}$ \\
\hline Land use & $\mathrm{X}$ & $\mathrm{X}$ & & & & $\mathrm{X}$ & $\mathrm{X}$ & $\mathrm{X}$ \\
\hline Population density & & & & & & & $\mathrm{X}$ & $\mathrm{X}$ \\
\hline $\begin{array}{c}\text { The relative value of } \\
\text { education }\end{array}$ & $\mathrm{X}$ & $\mathrm{X}$ & $\mathrm{X}$ & $\mathrm{X}$ & $\mathrm{X}$ & $\mathrm{X}$ & & \\
\hline $\begin{array}{l}\text { The rate for giving } \\
\text { support to the elder }\end{array}$ & $\mathrm{X}$ & $\mathrm{X}$ & & $\mathrm{X}$ & $\mathrm{X}$ & & & \\
\hline Enterprise return & & & & & & $\mathrm{X}$ & $\mathrm{X}$ & $\mathrm{X}$ \\
\hline Artificial facilities & & $\mathrm{X}$ & & $\mathrm{X}$ & & $\mathrm{X}$ & $\mathrm{X}$ & \\
\hline $\begin{array}{c}\text { Environmental } \\
\text { Geography }\end{array}$ & $\mathrm{X}$ & $\mathrm{X}$ & & & & & $\mathrm{X}$ & $\mathrm{X}$ \\
\hline Socio-economic & & & & & & $\mathrm{X}$ & $\mathrm{X}$ & $\mathrm{X}$ \\
\hline Total assessment & & $\mathrm{X}$ & & & & & $\mathrm{X}$ & $\mathrm{X}$ \\
\hline
\end{tabular}

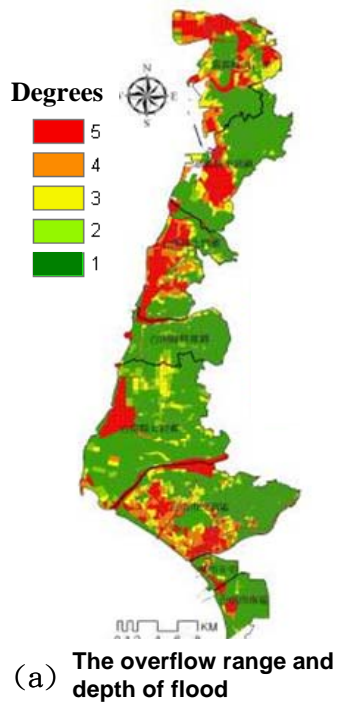

(A) Coastal hazard indexes (present)

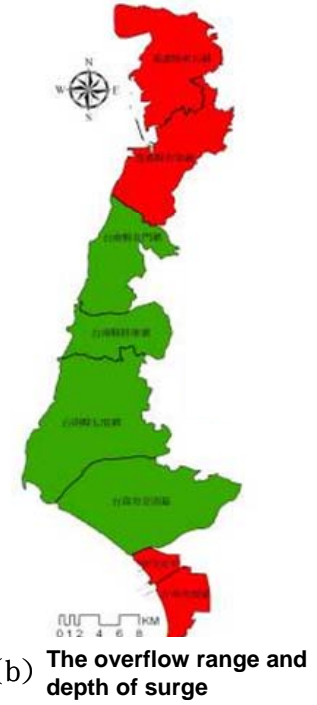

The overflow range and
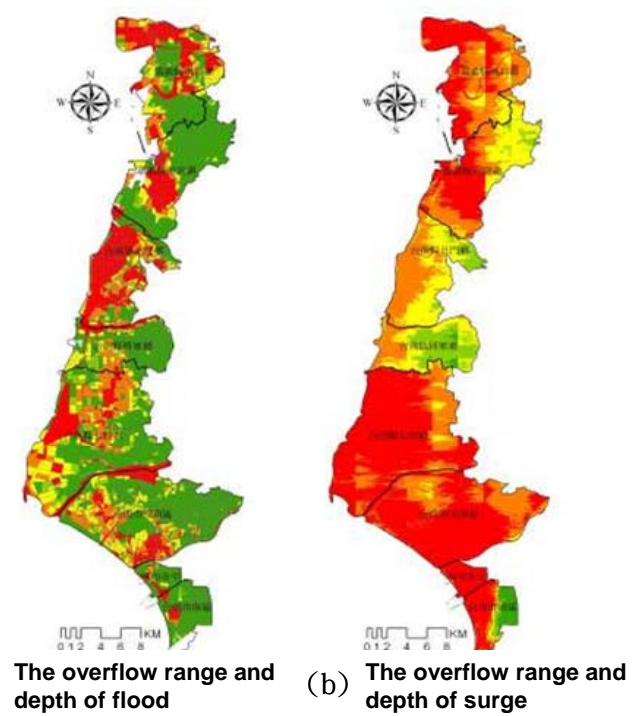

(B) Coastal hazard indexes (scenario)

Figure 15. The results of Coastal Hazard Indexes (CHI) of hazard potential analysis in Chiayi and Tainan coastal areas. 


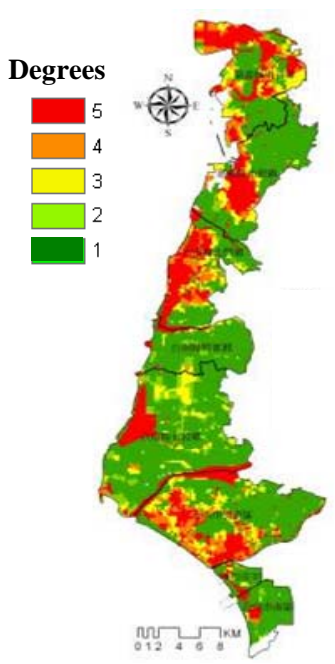

(a) Equal weighting

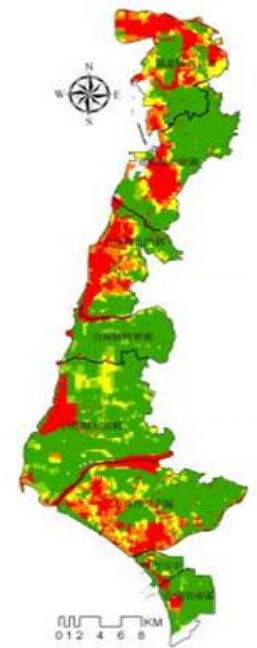

(b) AHP weighting

(A) Coastal hazard analysis (present)

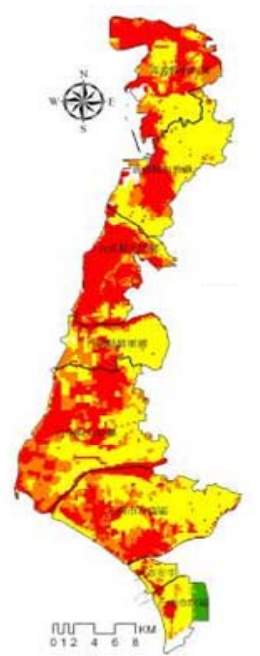

(a) Equal weighting

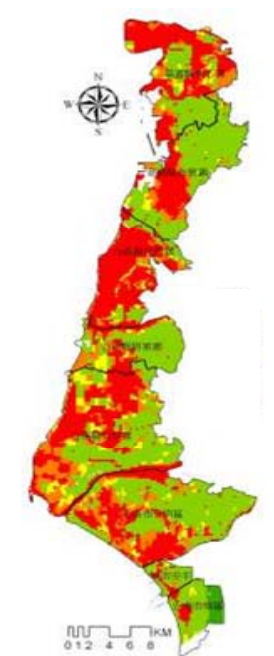

(b) AHP weighting

(B) Coastal hazard analysis (scenario)

Figure 16. The results of hazard potential analysis in Chiayi and Tainan coastal areas.

\section{(d) The risk assessment of coastal disaster due to climate change}

Figure 17 illustrates the risk of coastal disaster damage resulted from the coastal vulnerability and hazard potential. The figure also shows that climate change will increase the disaster risk in southwestern coastal Taiwan. In a further investigation of the impact of climate change, Figure 18 and Table 5 show the difference estimation of disaster risk between the scenario and present situations in Chiayi and Tainan's coasts. According to the AHP analysis, the area ratio with level 3-4 of disaster risk by climate change will increase from $36 \%$ to $59 \%$ in 2039, and the area ratio of level 5 will increase from $13 \%$ to $33 \%$.

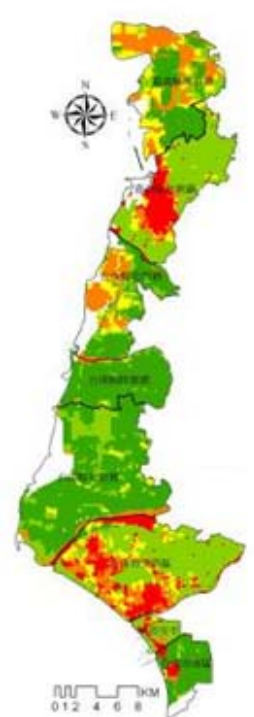

(a): Equal weighting

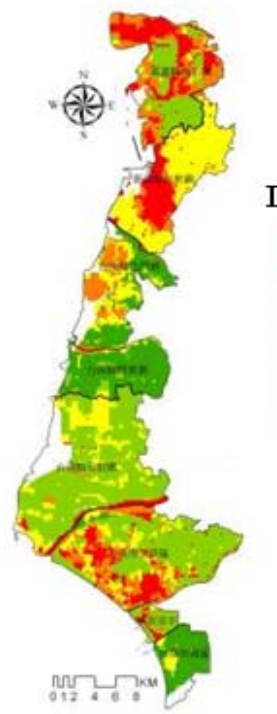

(b) AHP weighting

(A) Risk map (present)

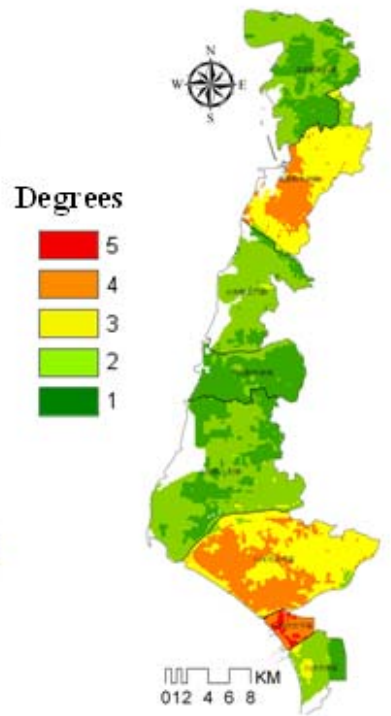

(a) Equal weighting

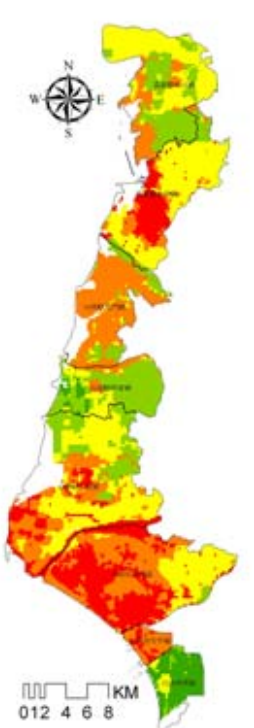

(b) AHP weighting

(B) Risk map (scenario)

Figure 17. The risk map of coastal disaster in Chiayi and Tainan coastal areas. 


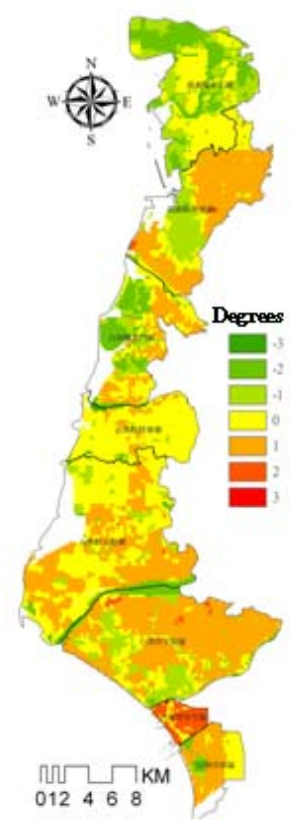

(a) Equal weighting

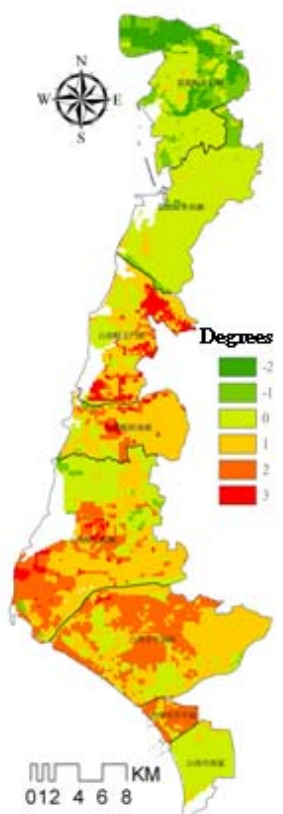

(b) AHP weighting

Figure 18. Difference of coastal disaster risk between the present and the time period of the scenario.

\begin{tabular}{|c|c|c|c|c|c|}
\hline & & & & & Unit: km² \\
\hline Items Level & 1 & 2 & 3 & 4 & 5 \\
\hline Present (equal weighting) & 204.28 & 258.6 & 50.00 & 68.44 & 44.12 \\
\hline Present (AHP) & 82.12 & 187.56 & 116.92 & 72.12 & 66.72 \\
\hline Scenario (equal weighting) & 5.60 & 146.28 & 182.20 & 153.28 & 37.56 \\
\hline Scenario (AHP) & 8.44 & 34.52 & 232.6 & 77.16 & 172.2 \\
\hline
\end{tabular}

\section{CONCLUSION}

The purpose of this paper is to integrate a future scenario of coastal vulnerability and risk assessment for the southwestern area of Taiwan (Chiayi and Tainan Coasts) and to develop corresponding vulnerability and risk charts for damage would potentially be caused in the future by climate change. In respect to the trend estimation of sea level rise, three different numerical methods were used to analyze the change of sea levels in southwestern Taiwan. The result shows that the rises in sea level are in the range of 10.19 to $14.57 \mathrm{~cm}$ during the time period spanning from 2020 to 2039 . For the vulnerability of coastal hazards occurring due to climate change we performed extensive disaster risk assessment, the present study investigates the vulnerability domains of artificial facility, environmental geography and socio-economics. Different coastal states will face different mainimpacts induced by climate change. The appropriate impact analysis and risk assessment can provide required data for adaptation capacity of coastal disasters due to climate change.

\section{ACKNOWLEDGMENTS}

This study was financially supported by the research project of Water Resources Agency, Ministry of Economic Affairs of Taiwan under grant numbers MOEAWRA0990334, MOEAWRA1000075 and MOEAWRA1010204.

\section{REFERENCES}

Cutter, S. L. 1996. Vulnerability to environmental hazards, Progress in Human. Geography, 20(4), 529-539.

Doukakis, E.. 2005. Coastal vulnerability and risk parameters. European Water, 11/12, 3-7. 
Hong, H., S. Cui, and L. Zhang. 2006. A coastal vulnerability index and its application in Xiamen, China. Aquatic Ecosystem Health \& Management, 9(3), 333-337.

Kavi Kumar K. S., and S. Tholkappian. 2006. Relative vulnerability of Indian coastal districts to sealevel rise and climate extremes. International Review for Environmental Strategies, 6(1), 3-22.

Lin, S. C., and T. Y. Tang. 2003. Factor Assessment of the Environmental Impact for Tainan Technology Industry Area in Taiwan. in: Ecosystems and Sustainable Development, Volume I, Edited by E. Tiezzi, C. A. Brebbia and J. L. Uso, WIT Press, Boston, 219-229.

Özyurt, G.. 2007. Vulnerability of coastal areas to sea level rise: a case study on Göksu Delta. Ankara, Turkey: Middle East Tech- nical University, Master's thesis, 99p.

UNDRO. 1980. Natural Disasters and Vulnerability Analysis, Report of Experts Group Meeting, UNDRO, Geneva.

UNEP. 2005. Assessing Coastal Vulnerability: Developing a Global Index for Measuring Risk. http://www.unep.org/. 